\title{
Dexmedetomidine and low-dose ketamine provide adequate sedation for awake fibreoptic intubation
}

\author{
[La dexmédétomidine et une faible dose de kétamine assurent une sédation \\ adéquate pendant l'intubation fibroscopique vigile]
}

Corey S. Scher MD, Melvin C. Gitlin MD

Purpose: We report the use of the alpha ${ }_{2}$ agonist, dexmedetomidine, with low-dose ketamine as a safe and effective treatment strategy to provide adequate comfort and sedation for a patient who fulfilled criteria of a difficult airway and required awake fibreoptic intubation (AFOI).

Clinical features: A 52-yr-old male with prostate cancer presented for radical prostatectomy. He reported several failed intubations with previous surgeries and airway examination was consistent with a difficult intubation. In addition, previous fibreoptic intubations were unsuccessful. The patient reported extreme apprehension concerning his airway management.

The goal of medicating patients for AFOI includes providing comfort and sedation without causing a change in ventilatory status. Dexmedetomidine has a high affinity for the alpha 2 receptor and results in sedation without change in ventilatory status. In addition, dexmedetomidine is a potent anti-sialgogue which makes it desirable for cases involved with airway instrumentation. A loading dose of dexmedetomidine followed by a continuous infusion provided comfort and sedation within ten minutes. While bradycardia and hypotension have been reported with dexmedetomidine use, concurrent low-dose ketamine was employed in this case for it's cardiostimulatory properties and no bradycardia and hypotension were noted. The airway was anesthetized with selective nerve blocks and conditions for airway instrumentation were excellent. There was no change in oxygen saturation or ventilatory status during the administration of medications or airway manipulation. The patient was comfortable, sedated and tolerated the procedures well. There was no recall of the procedure.

Conclusion: Dexmedetomidine and concurrent low-dose ketamine provided sedation and comfort to this patient who required an AFOI.
Objectif : Nous signalons l'usage de l'agoniste alpha ${ }_{2}$, la dexmédétomidine, et d'une faible dose de kétamine comme stratégie sûre et efficace visant au confort et à la sédation d'un patient dont l'évaluation indiquait des difficultés d'intubation prévisibles et la nécessité d'une intubation fibroscopique vigile (IFV).

Éléments cliniques : Un homme de 52 ans, atteint d'un cancer de la prostate, a été admis pour une prostatectomie radicale. La mention d'intubations impossibles lors d'interventions chirurgicales antérieures concordait avec l'examen des voies aériennes qui laissait prévoir des difficultés d'intubation. Des intubations fibroscopiques précédentes avaient aussi échoué. Le patient s'est dit très inquiet de subir une intubation. La médication qui accompagne l'IFV vise le confort et la sédation sans causer de modification de l'état ventilatoire. Or, la dexmédétomidine présente une grande affinité pour le récepteur alpha ${ }_{2}$ et produit une sédation sans changer l'état ventilatoire. En outre, la dexmédétomidine est un puissant antisialgogue, propriété recherchée dans les cas d'exploration instrumentale des voies aériennes. La dose de charge de dexmédétomidine, suivie d'une perfusion continue, a procuré confort et sédation en moins de dix minutes. La bradycardie et l'hypotension sont parfois reliées à la dexmédétomidine mais, dans le cas présent, le fait d'y ajouter en même temps une faible dose de kétamine connue pour ses propriétés cardiostimulantes n'a entraîné ni bradycardie ni hypotension. Les voies aériennes ont été anesthésiées par des blocages nerveux sélectifs et les conditions de manœuvre instrumentale étaient excellentes. La saturation en oxygène ou l'état ventilatoire n'ont pas été modifié pendant la médication ou la manipulation des voies aériennes. Le patient se sentait bien et la sédation efficace a permis de bien tolérer la manœurre qui n'a pas été répétée.

Conclusion : La dexmédétomidine et une faible dose de kétamine concurrente ont fourni une sédation et un confort au patient dont l'état nécessitait une IFV.

From the Department of Anesthesiology, Tulane Health Sciences Center, New Orleans, Louisiana, USA.

Address correspondence to: Dr. Corey S. Scher, Department of Anesthesiology, Tulane Health Sciences Center, 1415 Tulane Ave. SL-4,

New Orleans, LA 70112, USA. Phone: 504-588-5903, Fax: 504-584-1941; E-mail: cscher@anes.tulane.edu Accepted for publication November 28, 2002.

Revision accepted March 03, 2003. 
W

HILE awake fibreoptic intubation (AFOI) is a common technique for patients who fulfill criteria for difficult intubation, patient comfort and adequate sedation during these procedures remain difficult to provide. Sedation for these procedures must avoid respiratory depression, yet allow the operator to perform nerve blocks of the airway and proceed with intubation without loss of airway. We report the use of a dexmedetomidine and low-dose ketamine regimen to perform fibreoptic intubation with excellent conditions consisting of a dry airway, patient comfort, sedation and cooperation.

\section{Case report}

A 52-yr-old male, American Society of Anesthesiologists physical status II, was admitted for radical prostatectomy for diagnosis of prostate cancer. In addition to smoking, his medical history was remarkable for multiple back surgeries with instrumentation. As back pain persisted, he returned for back surgery at a different institution four months prior to this hospital admission. He reported that surgery was cancelled after several attempts at intubation with direct laryngoscopy under general anesthesia. He also reported that awake fibreoptic intubation (AFOI) was also attempted and was unsuccessful. Since that event, he wears a medical alert bracelet that describes him as having a difficult airway. The patient recalled severe dysphagia after all previous surgeries. He was told in his twenties that he had a difficult airway but failed to report this to future anesthesiologists. In addition, the patient reported that previous epidural steroid injections for back pain increased his back pain and refused a regional anesthetic for this procedure.

We contacted the institution where his previous surgery was cancelled and obtained a copy of his anesthetic record, which supported the patient's description of the events in the operating room. In addition, the record revealed difficulty ventilating his lungs with both a number 4 and 5 laryngeal mask airway. During his preoperative assessment, the patient expressed severe apprehension and anxiety concerning management of his airway.

On physical examination, the patient was $1.6 \mathrm{~m}$ tall and weighed $81 \mathrm{~kg}$. Blood pressure was 132/78 and pulse was 82 beats. $\mathrm{min}^{-1}$. Physical examination exclusive of the airway was remarkable only for multiple scars on his back extending from T6-L5. Airway examination revealed a thyromental distance of $2.5 \mathrm{~cm}$, a Mallampati score of 4 , and a mildly receding mandible. There were no protruding teeth and dentition was excellent. The patient's mouth opening was in excess of $40 \mathrm{~mm}$ and neck range of motion was normal.
In the preoperative holding area, members of the anesthesia care team counselled the patient. An $i v$ line was inserted, and, despite requests from the patient, no sedation was administered prior to entry into the operating room. Members of the otolaryngology service were notified and were immediately available. The anesthetic plan included evaluation of the airway with direct laryngoscopy and fibreoptic intubation if the vocal cords could not be visualized.

Electrocardiogram, blood pressure cuff and a pulse oximeter were applied and the patient was informed concerning these plans. The patient was instructed that we would not proceed with our evaluation and intubation until he was comfortable. The plan for sedation and comfort included infusions of the alpha ${ }_{2}$ agonist, dexmedetomidine and low-dose ketamine.

The patient received a bolus of dexmedetomidine $1 \mu \mathrm{g} \cdot \mathrm{kg}^{-1}$ (Precedex-Abbott Laboratories, North Chicago, IL, USA) over ten minutes. After the bolus, the infusion was set at $0.7 \mu \mathrm{gg} \cdot \mathrm{kg}^{-1} \cdot \mathrm{hr}^{-1}$. Neither hypotension or bradycardia were noted during dexmedetomidine administration. The patient reported comfort and sedation at the termination of the loading dose. The patient was rousable at all times, but when left unstimulated, tended to sleep. No changes in oxygen saturation and respiration were noted during the bolus or maintenance infusion. Upon completion of the dexmedetomidine bolus, 15 $\mathrm{mg}$ of ketamine were administered as a bolus and an infusion of $20 \mathrm{mg} \cdot \mathrm{hr}^{-1}$ was initiated. After the ketamine bolus, and during the infusion, the patient reported that he was calm, comfortable, sedated and stated that he was ready for the fibreoptic intubation. This low dose of ketamine did not result in adverse changes in mental status. There continued to be no change in oxygen saturation and respiratory status. $\mathrm{He}$ did complain of dry mouth.

During the continuous drug infusion, blocks of the recurrent laryngeal nerve and internal branch of the superior laryngeal nerve bilaterally were performed in the usual manner. ${ }^{1}$ The tongue and hypopharynx were sprayed with benzocaine. The patient remained both sedated and cooperative during these blocks. A Macintosh laryngoscope (\#4 blade) was inserted and the patient remained very cooperative although the epiglottis and vocal cords were not visualized.

An endoscopic oral airway was placed in the mouth and fibreoptic intubation was performed. The endoscopist noted excellent conditions including a secretion free airway. The patient was able to respond to requests to take slow, large deep breaths. The epiglottis and vocal cords were visualized and intubation proceeded without difficulty. General anesthesia was then 
induced and the drug infusions were discontinued. After an uncomplicated surgery, the trachea was extubated after the patient met criteria for extubation. The patient had no recall of the nerve blocks, direct laryngoscopy, or fibreoptic intubation.

\section{Discussion}

Various drug regimens have been described to facilitate patient comfort and cooperation for AFOI. Both fentanyl and midazolam have been used in combination for awake intubations. Clinicians are familiar with the respiratory depression that these drugs cause. ${ }^{2}$ While both of these agents may be reversed with naloxone and flumazenil respectively, desaturation may be profound, and full recovery of a normal respiratory status and oxygen desaturation may not occur in a timely manner. Droperidol and other butyrophenones provide excellent sedation without respiratory depression but are noted for their side effects. Doses that are used for fibreoptic intubations are associated with dysphoria, akathisia, and a prolonged state of sedation. ${ }^{3}$ While controversial, of recent, some reports have linked butyrophenones with poor outcomes in patients susceptible to prolonged Q-T syndrome. ${ }^{4,5}$

Dexmedetomidine, an alpha ${ }_{2}$ agonist, is an effective sedative and analgesic agent widely used for patients requiring postoperative ventilation in the intensive care unit. ${ }^{6}$ Dexmedetomidine sedation does not cause respiratory depression. ${ }^{7}$ In addition, xerostomia is commonly reported by patients. These two effects make dexmedetomidine highly desirable for AFOI. The characteristics of dexmedetomine sedation have been compared to propofol in the intensive care setting. ${ }^{8,9}$ Unlike patients sedated with propofol, patients receiving dexmedetomidine are easily roused to cooperate with medical procedures without expressing irritation. This quality is helpful when patients are asked to take deep inspirations or clear secretions during fibreoptic intubation. The relative sympatholysis achieved during dexmedetomidine infusions is an additional benefit in a procedure that may lead to elevations of heart rate and blood pressure. While bradycardia and hypotension have been reported with dexmedetomidine, this was not observed in this patient receiving a concurrent ketamine infusion. ${ }^{10}$ In this case, the patient did not recall fibreoptic intubation. While lowering of bispectral index scores and partial amnesia have been reported ${ }^{11}$ the true amnestic qualities of dexmedetomidine have yet to be defined. The coexisting infusion of ketamine may have contributed to the amnesia observed in this case. ${ }^{12}$

Ketamine was selected to take advantage of its minimal impact on ventilatory drive and analgesic proper- ties. The undesirable feature of increased airway secretions with ketamine administration was attenuated by the xerostomia induced by dexmedetomidine. In addition, dexmedetomidine attenuates ketamineinduced cardiostimulatory effects and drug-induced delirium. ${ }^{13}$ The patient did not report hallucinations nor vivid dreams. The initial loading dose of $15 \mathrm{mg}$ and infusion of $20 \mathrm{mg} \cdot \mathrm{hr}^{-1}$ is considered a low dose by most clinicians. It has been suggested that low-dose ketamine infusion ( $\left.4 \mathrm{ug} \cdot \mathrm{kg}^{-1} \cdot \mathrm{min}^{-1}\right)$, effectively lowers postoperative narcotic requirements without significant effect on mood, perception and cognition. ${ }^{12}$

While the interactions of dexmedetomidine and ketamine on ventilatory drive, analgesia, sedation, amnesia, and cardiovascular variables remain unclear, this combination did provide us with excellent conditions for AFOI, including satisfactory sedation, patient cooperation and a dry airway.

\section{References}

1 Hagberg $C A$. Preparation of the Patient for Awake Intubation. Handbook of Difficult Airway Management, lst ed. 2000: 70-1.

2 Bailey PL, Pace NL, Ashburn MA, Moll JW, East KA, Stanley TH. Frequent hypoxemia and apnea with sedation with midazolam and fentanyl. Anesthesiology 1990; 73: 826-30.

3 Kallos T, Smith TC. The respiratory effects of Innovar given for premedication. Br J Anaesth 1969; 41: 303-6.

4 Haddad PM, Anderson IM. Antipsychotic-related QTc prolongation, torsade de pointes and sudden death. Drugs 2002; 62: 1649-71.

5 Ben-David B, Weber S, Chernus S. Droperidol "box warning" warrants scrutiny (Letter). Anesthesiology 2002; 97: 288

6 Venn RM, Bradshaw CJ, Spencer R, et al. Preliminary UK experience of dexmedetomidine, a novel agent for postoperative sedation in the intensive care unit. Anaesthesia 1999; 54: 1136-42.

7 Belleville JP, Ward DS, Bloor BC, Maze M. Effects of intravenous dexmedetomidine in humans. I. Sedation, ventilation, and metabolic rate. Anesthesiology 1992; 77: 1125-33.

8 Venn RM, Grounds RM. Comparison between dexmedetomidine and propofol for sedation in the intensive care unit: patient and clinician perceptions. $\mathrm{Br}$ J Anaesth 2001; 87: 684-90.

9 Hall JE, Ubrich TD, Barney JA, Arain SR, Ebert TJ. Sedative, amnestic, and analgesic properties of smalldose dexmedetomidine infusions. Anesth Analg 2000; 90: 699-705.

10 Hogue CW Jr, Talke PK, Stein P, Richardson C, 
Domitrovich PP, Sessler DI. Autonomic nervous system responses during sedative infusions of dexmedetomidine. Anesthesiology 2002; 97: 592-8.

11 Mortero RF, Clark LD, Tolan MM, Metz RJ, Tsueda K, Sheppard $R A$. The effects of small-dose ketamine on propofol sedation: respiration, postoperative mood, perception, cognition, and pain. Anesth Analg 2001; 92: 1465-9.

12 Levanen J, Makella ML, Scheinin H. Dexmedetomidine premedication attenuates ketamine-induced cardiostimulatory effects and postanesthetic delirium. Anesthesiology 1995; 82: 1117-25.

13 Suzuki M, Tsueda K, Lansing PS, et al. Small-dose ketamine enhances morphine-induced analgesia after outpatient surgery. Anesth Analg 1999; 89: 98-103. 